\title{
Mecanismos de difusão de políticas sociais no Brasil: uma análise do Programa Saúde da Família
}

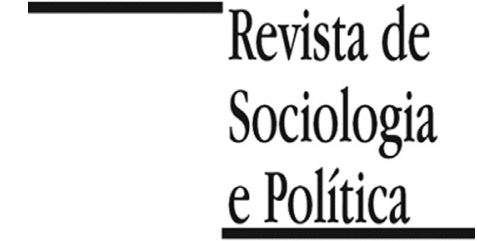

DOI 10.1590/1678-987316245807

\author{
Denilson Bandeira Coêlho, Pedro Cavalcante \\ e Mathieu Turgeon
}

\section{Resumo}

Nas últimas décadas, os estudos de difusão de políticas têm recebido grande atenção, especialmente nos EUA e na Europa. Estas pesquisas identificaram o papel dos fatores internos (características endógenas) e externos (características exógenas) para explicar fenômenos de difusão de inovações políticas. Os eventos de difusão, no entanto, também estão proximamente relacionados à questão temporal haja vista que muitas vezes as adoções ocorrem devido a existência simultânea de fatores em grandes intervalos de tempo. Neste trabalho, propomos explorar a difusão de políticas sociais de saúde no Brasil. O artigo inova ao analisar conjuntamente o papel dos fatores internos e externos usando uma unidade de análise não convencional para o campo de estudos, ou seja, governos locais. Para a análise é importante notar que a Constituição de 1988 reconhece os municípios como jurisdições autônomas, dando-Ihes a prerrogativa constitucional para adotar ou não uma política social do governo federal. Que fatores determinam a difusão do Programa Saúde da Família? Para responder essa questão aplicamos a metodologia Event History Analysis utilizando dados para cerca de 5.560 municípios no período 1997-2010. Os resultados demonstram que competição política e ideologia influenciam a difusão horizontal e vertical entre os municípios. Surpreendentemente, eleições municipais também influenciam a emulação da política.

PALAVRAS-CHAVE: difusão de políticas; programa saúde da família; governos municipais; competição política; análise de sobrevivência.

Recebido em 1 de Janeiro de 2015. Aprovado em 14 de Março de 2015.

\section{Introdução*}

\author{
* Agradecemos aos \\ comentários e sugestões \\ realizados pelos pareceristas \\ anônimos da Revista de \\ Sociologia e Política.
}

\begin{abstract}
A Ciência Política tem desenvolvido novas abordagens para estudar comparativamente processos de mudança política. O campo de estudos que analisa a formação de agenda e os determinantes do processo decisório vem sendo influenciado por vertentes teóricas neoinstitucionalistas que focam o papel do Estado e a complexa interação com grupos de interesse, partidos e sociedade civil. Assim, novas concepções passaram a analisar os fenômenos da difusão de políticas entre governos nacionais e subnacionais. Walker (1969) em seu estudo seminal analisou as razões que explicam a emulação de programas entre os estados americanos. A partir desse estudo outras colaborações surgiram em áreas e temas como direitos civis, educação, tecnologia, Judiciário, constituição, modelos econômicos, democracia, privatizações e modelos de bem-estar (Gray 1973; Menzel \& Feller 1977; Regens 1980; Glick 1981; Mintrom 1997b; Simmons \& Elkins 2004; Brinks \& Coppedge 2006). O interesse central em estudos de difusão é saber o que causa a adoção de um novo programa por outros governos. Por que alguns governos adotam determinadas políticas públicas enquanto outros governos não adotam? Por que certas inovações de políticas se disseminam? O que explica a velocidade do processo de difusão? Estas são algumas das questões relevantes que a literatura tem investigado com foco no federalismo americano e no continente europeu. Estas análises contribuem para conhecermos os fundamentos das
\end{abstract}


decisões políticas em torno de inovações institucionais em diferentes áreas. Entretanto, esses estudos contemplam apenas um número limitado de casos (Small-N studies) e não exploram os mecanismos multidirecionais da adoção de políticas que incluem a ocorrência simultânea de processos horizontais e verticais no tempo.

Até meados dos anos 1990 duas vertentes teóricas polarizaram o debate acerca de modelos explicativos de difusão: os determinantes internos e externos. O primeiro afirma que os fatores que conduzem a difusão são as características econômicas, políticas e sociais das unidades adotantes, enquanto o segundo pressupõe que são as redes formais e informais e a proximidade geográfica que influenciam a adoção. Contudo, mais recentemente a literatura tem convergido para uma posição crítica a respeito das fraquezas dessa divisão teórica que falha ao não capturar a complexidade dos fenômenos de difusão (Berry \& Berry 1990; 2007; Mintrom 1997a; Volden 2006; \& Volden 2006).

Com base na contribuição desses trabalhos, o arcabouço teórico do artigo unifica teorias rivais para testar ambos os determinantes da difusão de políticas públicas no Brasil. Na literatura nacional, a aplicação de teorias de difusão é ainda muito incipiente. Contudo, por ser uma federação altamente descentralizada, onde as esferas subnacionais de governo possuem autonomia para implementar políticas, o caso brasileiro na verdade representa uma importante unidade de análise comparativa. A emulação de políticas de controle orçamentário, transferência de renda e um conjunto diversificado de programas sociais são exemplos empíricos que configuram uma agenda de pesquisa promissora. Neste trabalho o caso analisado é o Programa Saúde da Família (PSF). O PSF surgiu em alguns municípios que já haviam implantado o Programa de Agentes Comunitários da Saúde (PACS). No período analisado, 1991 a 2010, as taxas de adoção municipal ao PSF foram crescentes, mas chama a atenção o fato de que a difusão da política tenha se prolongado por mais de duas décadas. Por apresentar taxas de adoção fragmentadas no tempo e por não ter sido um processo automático de cópia ou descentralização federativa, o caso brasileiro apresenta excepcionalidades.

Em linhas gerais o problema de pesquisa que orienta o estudo é investigar que fatores de natureza política, institucional e regional influenciaram a decisão dos governos municipais para a adoção do PSF. Ao testar os determinantes que influenciam a difusão do PSF numa análise comparativa que mensura o comportamento político do Executivo local, o trabalho pretende contribuir, em termos teórico-metodológicos, demonstrando como uma análise multimétodo que contempla metodologia qualitativa e quantitativa permite o mapeamento histórico do processo.

Para cumprir os objetivos propostos, conduzimos uma análise inédita sobre a implementação do PSF que considera ambas as difusões horizontal - entre 5.564 municípios -, e vertical - do governo federal para os governos locais. A análise será feita por meio da modelagem estatística Event History Analysis $(\mathrm{EHA})^{1}$ que permite mensurar no tempo o efeito dos determinantes internos e externos sobre a adoção de políticas. A intenção é contribuir com a literatura a partir de um estudo de tipo large- $N$ que investiga simultaneamente os mecanismos direcionais de difusão horizontal, bottom-up e topdown. Embora muito conhecimento tenha sido apreendido sobre a difusão entre estados nos EUA e países da Europa, ainda sabemos pouco a respeito da difusão entre municípios. A análise é, portanto, um passo crucial para sabermos em que condições uma política municipal de saúde gera pressões no sistema político que resultam na sua federalização. A análise também é fundamental para se entender o funcionamento de sistemas federais em ambientes institucionais marcados por uma alta oferta de políticas. Destacamos que os governos locais no Brasil são

\footnotetext{
1 Análise da História do Sobrevivência é utilizada pela permite mensurar em que oconcias uma mudanc período no tempo. Em consonância com os trabalhos desse campo de estudos, este artigo utiliza as noções de "risco", "eventos de falha" e "tempo", os quais serão
} 
descritos na seção metodológica. significativamente distintos no que se referem aos aportes fiscais, qualidade da burocracia e necessidade de programas sociais. Assim, é razoável supor que o novo modelo de política de saúde seria adotado por unidades com baixos indicadores de saúde, mas com capacidade institucional para gerir a política.

Para o desenvolvimento da análise o artigo inicialmente apresenta o arcabouço teórico e as hipóteses. Em seguida a metodologia e seleção de variáveis é apresentada. A seção seguinte descreve o surgimento e a evolução do PSF, para ilustrar como a disseminação do novo modelo de saúde pode ser examinado sob as bases teóricas de difusão. Realizamos então os testes estatísticos usando o modelo de análise de sobrevivência para testar os determinantes do processo de emulação do PSF no país. A conclusão demonstra como atores locais tomam decisões quando programas sociais inovadores surgem em um sistema político altamente descentralizado e autônomo. Os achados demonstram também a relevância de testar a validade e o alcance de teorias clássicas como comportamento político, ideologia e redes para ilustrar como a variação de graus de adoção ocorre em longos períodos no tempo.

\section{Abordagens de Difusão de Políticas Públicas}

${ }^{2}$ Estudos de difusão horizontal entre municípios ocupam pouco espaço na literatura internacional. No Brasil, este tipo de análise começou a despertar o interesse dos pesquisadores a partir dos trabalhos de Sugiyama (2008a; 2008b), Wampler (2008), Spada (2010) e Coêlho (2012a; 2012b).
Na literatura nacional a explicação da difusão de políticas públicas é fortemente baseada em postulados teórico-conceituais de caráter institucionalista com grande ênfase no papel indutor do governo central e a capacidade efetiva de financiamento e repasse de recursos para os governos subnacionais. Os modelos dos múltiplos fluxos (Kingdon 1995) e equilíbrio pontuado (Baumgartner \& Jones 1993) são os que, entre os modelos neoinstitucionalistas, que mais privilegiam a noção conceitual de difusão de políticas. Kingdon (1995) pressupõe que a formação de agenda ocorre quando, por meio da atuação de um empreender político, três fluxos independentes se acoplam formando uma janela de oportunidades para a formulação de políticas e posterior disseminação da ideia em redes formais e informais do sistema político. Baumgartner e Jones (1993), ao analisarem arenas políticas tradicionais, explicam que trajetórias históricas são interrompidas em momentos críticos quando feedbacks positivos alteram a imagem de uma questão política de forma que o seu desenho institucional é alterado tendo como resultado a replicação do novo modelo de política por outros governos.

Estudos sobre difusão de políticas têm cada vez mais tomado a atenção de especialistas que se preocupam em explicar por que e como ocorre a disseminação de novos desenhos institucionais entre países, estados ou municípios ${ }^{2}$. A disseminação de modelos de políticas não necessariamente resulta numa distribuição uniforme. Ao contrário, há significativa variação de caso para caso. De acordo com Elkins e Simmons (2005), este é um ponto crucial no debate sobre o conceito de difusão. Os autores argumentam que, na verdade, é esperado que não ocorra harmonização, tamanha a complexidade do fenômeno e o conjunto de fatores que o envolve. Assim, ondas de difusão coordenadas por agências ou partidos implicam um alto grau de conectividade entre países ou governos subnacionais (Kerr 1983; Huntington 1991; Powell \& Dimaggio 1991; Drezner 2001). Em outro cenário, ondas de difusão não coordenadas implicam um menor grau de interconexão entre governos (Ikenberry 1990; Bennett 1991; Dolowitz \& Marsh 2000). O que aproxima as duas correntes é o reconhecimento da interdependência entre as unidades que emulam as políticas no sentido que a decisão governamental de adotar uma dada política é alterada pelas escolhas prévias. Segundo Rogers (1995), a difusão de políticas é cumulativa no tempo. A adoção tem início em um grupo de adotantes denominados inovadores, grupo que se distingue dos demais em razão de pôr em prática suas ideias inovadoras. A replicação da nova solução política depende de um con- 
junto de variáveis básicas e específicas. Nessa perspectiva, as taxas de adoções ocorrem a partir de diferentes frequências entre os primeiros adotantes (baixa), depois entre os adotantes intermediários (grande) e finalmente entre os últimos adotantes (muito baixa, até cessar). O Gráfico 1 informa a distribuição categórica de atores inovadores e potenciais adotantes, segundo suas estratégias de ação política.

Uma possibilidade de se aprofundar esse debate se apresenta quando comparamos as abordagens de determinantes internos em contraposição aos determinantes externos. Por um lado, autores como Downs (1976) e Regens (1980) não reconhecem a influência dos determinantes externos. Por outro lado, Grupp e Richards (1975) e Light (1978) assumem a irrelevância dos fatores internos. Embora esses estudos tenham sido realizados há mais de 30 anos, o fato é que ainda hoje a divisão encontra espaço na literatura. Este debate teórico tomou novo rumo quando em 1990 foi lançado um estudo sobre a adoção de loterias estaduais entre os estados americanos. Além de romperem com a lógica dualista vigente, Berry e Berry (1990) deram grande contribuição teórico-metodológica para a área de estudos de difusão. Os autores unificaram as duas teorias e demonstraram que é irrealístico supor que as decisões de mudança política são determinadas isoladamente ou por influência dos vizinhos ou pelos atributos locais. $\mathrm{O}$ argumento utilizado para qualificar a análise conjunta encontra apoio teórico em Mohr (1969) a partir da noção de que a propensão de inovar é uma função diretamente associada: i) às motivações; (ii) à força dos obstáculos contra a inovação e (iii) à disponibilidade de recursos para se ultrapassar os obstáculos. Em síntese, a tomada de decisão diz respeito ao comportamento individual, mas também às dificuldades internas e externas que constrangem os atores políticos.

\section{II.1. A abordagem dos Determinantes Internos}

O modelo de determinantes internos pressupõe que a decisão de emular uma política está fortemente associada às características locais das jurisdições. Importam elementos como as condições sociais e econômicas da população, capacidade institucional, ideologia e o grau de competição política. Uma parte

Gráfico 1 - Distribuição categórica de potenciais adotantes de políticas inovadoras

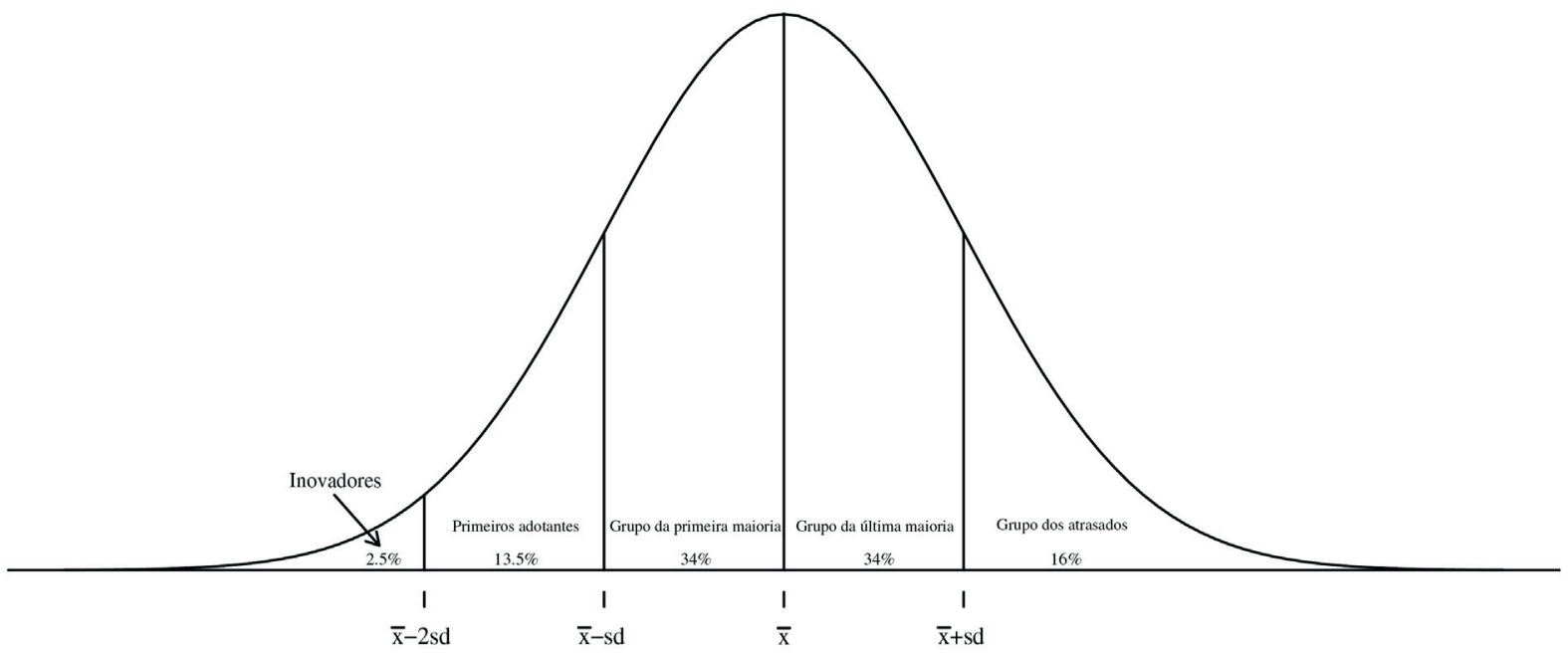

Fonte: Os autores.

A base do gráfico retrata os valores do desvio-padrão do universo de atores que criam e reproduzem políticas inovadoras. Dois desvios-padrão abaixo da média correspondem a 13,5\% da população, um desvio-padrão abaixo da média corresponde a 34\%, um desvio-padrão acima corresponde a $34 \%$ e dois desvios-padrão acima correspondem a $16 \%$. 
3 A literatura de Reforma Social que tem como expoentes Kaufman e Nelson (2004), que pesquisam a influência de firmas, sindicatos e partidos oposicionistas como veto players de reformas. A explicação é que esses grupos de interesse desejam manter seu status quo e posição ideológica. Nessa visão, os governantes, portanto, dispõem de poder decisório limitado para emular receitas universais de outros países. da explicação que sustenta a importância dos determinantes internos é que os políticos tomadores de decisão sofrem constrangimentos quando escolhem adotar uma política. Políticos vão arcar com custos concentrados caso o modelo implantado falhe. Assim, os políticos necessariamente buscam dispor de um conjunto de recursos para ultrapassar os obstáculos, mas sempre com a preocupação de serem bem avaliados pelos eleitores. Em um ambiente onde há demandas para maior oferta de assistência social, cobertura de saúde ou educação, provavelmente decisões de governo por reformas serão tomadas (Mintrom \& Vergari 1998; Stream 1999; Allard 2004). Entretanto, outros fatores, como (i) capacidade de financiamento da política, (ii) posição ideológica dos atores e (iii) relações Executivo-Legislativo informam que o quadro é muito mais complexo, o que indica um alto grau de tensão para a decisão de adotar uma política $^{3}$. A abordagem teórica que considera a ideologia como um fator que influencia decisões governamentais preconiza que certos atores formulam políticas voltadas prioritariamente para grupos vulneráveis da população. Teóricos como Mullins (1972) e Boushey (2010) consideram que alguns indivíduos são guiados por valores e crenças que os tornam mais receptivos às mudanças institucionais com ênfase no social em comparação com outros indivíduos de perfil conservador. Governantes frequentemente tomam conhecimento de novas práticas na administração pública por meio de redes de políticas públicas ou em decorrência de pressões partidárias. Nessa perspectiva, uma das limitações dessa abordagem é que não fica exatamente claro se a motivação individual de adotar a política sofreu alguma influência de uma onda nacional ou regional de difusão. Mas é importante enfatizar que embora o modelo não desconsidere tais eventos, preconiza que os atributos internos é que de fato determinam ou não a emulação de políticas.

\section{II.2. A abordagem dos Determinantes Externos}

\footnotetext{
4 A literatura de redes em estudos de difusão analisa o impacto das policy networks
}

O modelo de determinantes externos pressupõe que governos adotam políticas porque são influenciados por outros governos através da propagação da comunicação em redes institucionalizadas ou informais. A abordagem apresenta duas visões distintas, relacionadas ao recorte territorial. Um dos pressupostos é que, atuando em redes de alcance nacional, burocracias aprendem com seus pares e emulam políticas ou procedimentos de gestão pública. Segundo Gray (1973), a probabilidade de adoção está associada ao número de interações. Um exemplo seria uma associação que reúne estados ou municípios para comunicar e estimular as unidades a emularem uma política inovadora já adotada por alguns governos. A diferença crucial entre as duas abordagens é a variável proximidade geográfica. Enquanto que no modelo nacional a interação entre as unidades ocorreria em todo o território de um país, no modelo regional a interação acontece por região. Nos dois modelos haveria vínculos constantes entre os atores que assim trocariam informações gerando um processo de aprendizado que orientaria suas decisões de emular políticas. Em razão do problema do mapeamento espacial, o modelo de influências regionais surgiu como uma abordagem mais realística ao definir mais apropriadamente a variável território e as conexões de redes entre os governos. Conforme assinalam Mintrom e Vergari (1998), um dos problemas clássicos de estudos de difusão é a falta de atenção dada para a modelagem dos mecanismos através dos quais as ideias políticas são comunicadas entre os estados. O que os autores concluem é que muitas dessas acepções não têm validade porque não foram testadas empiricamente. Sua definição de Rede de Políticas afirma que consiste em um grupo de atores que dividem interesses em algumas áreas de políticas estando ligados por seus contatos diretos e indiretos ${ }^{4}$. As primeiras contribuições para esse debate testaram a hipótese de que estados mais similares economicamente e socialmente tendiam a emular seus vizinhos mais próximos em razão da 
em mudanças políticas. Por exemplo, Adam e Kriesi (2007) consideram como o tipo de interação entre os atores determina a mudança política.

5 O autor evidencia que estados que possuem arranjos institucionais similares são mais propensos a difundirem políticas regulatórias entre si, independentemente da localização geográfica. $\mathrm{O}$ estudo constata que estados com associações profissionais e comissões de seguro de saúde replicaram em taxas maiores o Ato Nacional da Health Maintenance Organization (HMO) que regulamenta as atividades do setor.

${ }^{6} \mathrm{O}$ autor atesta que estados vizinhos com políticos empreendedores - atores que promovem novas soluções para o sistema político aprovaram, em comparação com outros estados, mudanças na legislação educacional (como, por exemplo, a definição de prêmios para as escolas com melhor desempenho acadêmico). identificação de problemas comuns e da possibilidade de melhor performance das políticas (Elazar 1972). Estudos mais recentes demonstram que a proximidade geográfica assume menor ou pouca importância quanto mais equânimes forem as propriedades das unidades potencialmente adotantes (Balla 2001 Mintrom $1997 b^{6}$ ). Entretanto, outros estudos têm apontado a relevância do efeito de vizinhança ao ilustrarem empiricamente a ocorrência de competição intergovernamental entre estados geograficamente próximos (Baybeck, Berry \& Siegel 2011).

A partir dessas vertentes analíticas, desenvolvemos hipóteses específicas para testar as teorias de difusão para o caso do PSF. Seguindo a tendência mais recente da literatura, o modelo explicativo incorpora tanto a abordagem dos determinantes internos quanto externos. Conforme descrito, a primeira abordagem preconiza que a difusão é resultante de aspectos políticos, econômicos e sociais que em grande medida moldam os incentivos e constrangimentos relativos à tomada de decisão dos atores políticos. Por outro lado, a segunda abordagem pressupõe que a decisão de adotar um novo programa está diretamente associada à proximidade geográfica entre as potenciais unidades adotantes. No que concerne à dinâmica política, principal variável a ser testada no estudo, a expectativa é que as eleições propiciem aos cidadãos a oportunidade de avaliar os governantes (Manin \& Przeworski 1999). O processo eleitoral é o principal mecanismo de accountability utilizado pelos eleitores não apenas para punir os atuais ocupantes dos cargos, visão padrão do voto retrospectivo (Fiorina 1981), mas também para escolher os melhores governantes, sob a ótica do voto prospectivo (Maravall 1999). No caso brasileiro, o grau de competitividade das eleições municipais para o Executivo atuaria como um fator de ameaça à sobrevivência política, de modo a estimular a implementação de inovações institucionais como o PSF. A partir dessa premissa o estudo testa de duas formas a influência de competição política municipal:

(i) Hipótese 1: Quanto menor o percentual de votos do candidato eleito, maior a propensão de se adotar o PSF.

(ii) Hipótese 2: Quanto maior o número efetivo de partidos e a divisão de votos no município, maior a propensão de se adotar o PSF.

Na esfera partidária, a primeira variável é a ideologia do partido do prefeito, onde o objetivo é mensurar o impacto desse aspecto sobre a adoção da política pública. A premissa teórica é que governos de esquerda tendem a ser mais intervencionistas e proativos na área social do que os governos de direita (Przeworski 1985). No caso brasileiro, de acordo com Mainwaring, Meneguello e Power (2000), os partidos de centro-direita tendem a apoiar políticas mais liberais enquanto legendas de esquerda defendem ações governamentais direcionadas à distribuição de renda. Nesse contexto, testamos a seguinte hipótese:

(iii) Hipótese 3: Municípios administrados por partidos políticos de esquerda têm maior probabilidade de adoção do PSF.

Ainda no âmbito dos partidos, outro aspecto relevante é o alinhamento partidário entre o governo municipal e o governo federal. Conforme a literatura indica, a convergência partidária entre governos de diferentes esferas reflete em maior cooperação em torno da implementação de políticas públicas (Cox \& McCubbins 1986). No caso do PSF, o Ministério da Saúde promoveu, principalmente a partir de 1998, um maior volume de repasses financeiros para cobrir custos de instalação do programa. Nesse sentido, almeja-se testar se o alinhamento político induziu a maior cooperação entre as esferas governamentais e consequentemente maior adesão ao PSF. 
${ }^{7}$ Embora o modelo de atendimento do PSF seja centrado em bases universalistas, as prioridades de cobertura estão voltadas para públicos específicos: i) Cobertura pré-natal e pós-natal, combate à mortalidade infantil, cobertura vacinal, nutrição e saúde bucal de crianças de 0 a 6 anos; (ii) promoção de saúde do idoso, sobretudo pacientes com tuberculose, hanseníase, hipertensão, diabetes e doenças crônicas. (iv) Hipótese 4: Prefeitos de partidos da base do governo federal possuem maior propensão para adotar uma nova política pública.

Os incentivos aos políticos inerentes ao processo eleitoral em si também são testados. Fundamentado nos pressupostos da teoria do ciclo político de negócios (Nordhaus 1975), pretende-se avaliar se a proximidade das eleições no âmbito municipal tende a impactar a disposição dos governantes em adotar o PSF, fator este já testado em estudos clássicos sobre conexão eleitoral ou de difusão de políticas públicas (Kiewiet \& McCubbins 1985; Berry \& Berry 1992). Assim, temos a seguinte hipótese:

(v) Hipótese 5: Em de eleições municipais é mais provável adotar uma nova política social.

Duas hipóteses relacionadas aos determinantes internos sociais são também testadas. O percentual da população com idade até 17 anos e a partir de 65 anos também pode ser considerado um fator que influencia a difusão do $\mathrm{PSF}^{7}$. De acordo com os objetivos do programa essas são as faixas etárias prioritárias de atendimento social devido ao fato de que é justamente nesse período de vida em que as pessoas necessitam de mais tratamento médico. Considerando tal circunstância, é esperado que a maior demanda pela rede pública de saúde gere uma maior pressão sobre o prefeito para adotar o PSF.

(vi) Hipótese 6: Municípios com elevado percentual da população com até 17 anos de idade são mais prováveis de adotar políticas de atendimento básico de saúde.

(vii) Hipótese 7: Municípios com elevado percentual da população a partir de 65 anos de idade são mais prováveis de adotar políticas de atendimento básico de saúde.

As próximas hipóteses incorporam a premissa basilar dos determinantes externos. Nessa abordagem, os municípios localizados geograficamente próximos a um município que criou um novo programa tenderiam a reproduzir a experiência do vizinho. A literatura explora os potenciais efeitos de vizinhança como um meio para mensurar indiretamente efeitos indiretos de redes políticas formais ou informais as quais propagam informações em diferentes sistemas de comunicação. Seguindo essa lógica, testamos os efeitos da adoção da política em unidades com maior proximidade geográfica na unidade Estado:

(viii) Hipótese 8: Quanto maior a proximidade geográfica com municípios do próprio Estado que criaram o PSF, maior é a probabilidade de um município também adotar o programa.

Ademais, é importante também considerar os efeitos de vizinhança do ponto de vista regional. De acordo com Walt (2000), programas sociais normalmente se espalham em regiões inovadoras e posteriormente transferem-se para as demais regiões de um país. No caso do PSF, foram os municípios da região Nordeste os precursores do modelo, mas os municípios das regiões Sul e Sudeste são os que apresentam maiores similaridades em termos de envolvimento em redes políticas formais e informais. Portanto, é de se esperar que haja uma maior difusão nestas regiões.

(ix) Hipótese 9: A difusão da política será maior na região precursora e nas regiões onde as redes políticas formais e informais são mais ativas.

\section{Unificando teorias a partir da metodologia Event History Analysis}

O propósito central desta pesquisa é compreender a difusão das políticas públicas em uma federação com alto grau de descentralização político-administrativa. Conforme discutido na seção teórica, a questão central que norteia este 
${ }^{8}$ É importante enfatizar que as unidades analisadas do Grupo 2 não apresentaram falhas no tempo pesquisado, mas as unidades não estão livres de incorrerem em falhas no futuro (Allison 1984; Yamaguchi 1991).

\footnotetext{
${ }^{9} \mathrm{O}$ banco de dados da pesquisa foi estruturado no pacote estatístico Stata 12.
}

estudo investiga os fatores que influenciam alguns governos a adotarem determinadas políticas enquanto outros governos não adotam. Para operacionalizar a pesquisa, o estudo utiliza o modelo estatístico Event History Analysis (Análise de Sobrevivência, EHA na sigla em inglês). EHA vem sendo amplamente utilizado pela literatura de difusão porque permite calcular a influência de fatores internos e externos e mensurar a probabilidade de uma unidade de governo adotar uma dada política no tempo (Mooney 2001; Buckley \& Westerland 2004). Conforme Yamaguchi (1991) argumenta, pesquisas que utilizam EHA tem o objetivo de definir quais são os padrões e as causas de mudanças [políticas] no tempo. A principal vantagem em usar EHA para estudar a difusão de políticas é que o modelo captura as características temporais da mudança ao utilizar informações como o momento, a quantidade de casos, a sequência e a duração dos eventos (Box-Steffensmeier \& Jones 1997). Pesquisas que utilizam EHA focam, portanto, os processos de mudança no tempo com dados temporais longitudinais dando grande importância à dinâmica da estrutura temporal em uma clara substituição à pesquisas que focam uma relação temporal estática.

Os modelos de EHA em geral se referem às noções de "risco", "sobrevivência" e "falha" no sentido de que as unidades em análise estão sujeitas a experimentar um dado evento que passa a ocorrer mais frequentemente. Nessa perspectiva, EHA mensura, no tempo, o risco de as demais unidades governamentais serem influenciadas e assim adotarem ou não as inovações do sistema político. Na operacionalização do modelo, as unidades que não experimentam o evento são censuradas. Censura é a observação parcial da resposta, a qual foi interrompida não permitindo a observação do tempo de falha (adoção de uma política). Temos então dois grupos no universo pesquisado: Grupo 1, que apresenta falhas, e o Grupo 2, que não as apresenta ${ }^{8}$.

Uma preocupação prática para estimar o EHA é a estrutura do conjunto de dados da investigação. O argumento é que noções teóricas ajustadas devem guiar adequadamente a definição das hipóteses para mensurar a probabilidade do "risco" de emular uma política. Para refinar o estudo, o pesquisador deve conhecer o intervalo de tempo em que o fenômeno ocorreu para estabelecer o quadro de unidades que estiveram sob o risco de experimentar o evento. A abordagem de EHA possui duas formulações para estimar as mudanças políticas. No modelo de tempo discreto (discrete time models), a unidade está em risco a partir de tempos pré-definidos como o ano eleitoral ou a contagem em anos. No modelo de tempo contínuo (continuous-time model), o evento pode ocorrer em qualquer momento no tempo. Em qualquer formulação, uma vez que a falha ocorre, consequentemente os riscos para as outras unidades sobreviverem aumentam progressivamente.

No presente trabalho, devido à ausência de dados de variáveis associadas à dimensão política, um recorte temporal arbitrário foi definido. A difusão do PSF no Brasil ocorreu a partir de 1991, entretanto, o recorte temporal da pesquisa, para efeito dos testes econométricos, abarca o período 1997-2010, em razão da inexistência de dados eleitorais no Tribunal Superior Eleitoral (STE) para alguns estados da federação referente às eleições municipais de 1992. A opção metodológica encontra apoio na literatura que indica que nesses casos os eventos devem ser censurados à esquerda (Box-Steffensmeier 2007; Cleves et al., 2008). Assim, os primeiros 475 casos de adoção do PSF foram suprimidos da base de dados ${ }^{9}$. Desse modo, foram considerados 5.088 casos entre os 5.564 municípios do país. Uma vez que EHA requer observações temporais e dado que os fenômenos políticos, como a adoção de programas, ocorrem em grandes intervalos de tempo estimamos um modelo de riscos proporcionais de Cox usando o cálculo exato marginal para mensurar o peso de covaráveis nas ocorrências simultâneas de eventos de adoção do PSF. Em outras palavras, o modelo de Cox relaciona a variável resposta com variáveis independentes 
(fatores de risco) que estejam possivelmente associadas à falha ou ocorrência do evento.

III.1. Organização dos dados e das variáveis da pesquisa

Variável dependente: Adoção do PSF.

Como variável dependente, a pesquisa define a adoção municipal do PSF no período de 1997 a 2010, atribuindo valor 0 para os casos de não adesão e valor 1 para a adesão. Uma vez que um município adota o programa suas observações são excluídas da base de dados. Este procedimento é necessário para que o modelo EHA não recalcule o risco do mesmo município readotar o PSF. Os casos de não adoção até 2010 foram censurados à direita.

Variáveis independentes:

\section{(i) Competição Política Municipal (Percentual de Votos do Eleito)}

Média de votos válidos dos prefeitos eleitos nas eleições de 1996, 2000, 2004 e 2008. Variável dicotômica definida da seguinte forma: i) sistema político competitivo, quando o eleito vence as eleições com menos de $45 \%$ dos votos válidos, valor $=1$; (ii) sistema político não competitivo, quando o eleito vence o pleito eleitoral com mais de $45 \%$ dos votos válidos, valor $=0$. Todos os municípios que tiveram segundo turno são considerados como politicamente competitivos.

\section{(ii) Competição Política Municipal (Número Efetivo de Partidos)}

Elaborado por Golosov (2010) o Número Efetivo de Partidos (NEP) calcula a parcela de votos que os partidos obtêm em uma eleição majoritária. Considera-se que uma eleição é muito competitiva quando a fragmentação de votos partidários é alta. Atribui-se que uma disputa eleitoral é pouco ou não competitiva quando a proporção da divisão de votos partidários é baixa. Aplicamos então a seguinte fórmula:

$$
\mathrm{N}_{\mathrm{p}}=\sum_{\mathrm{i}=1}^{\mathrm{x}} \frac{1}{1+\left(\frac{\mathrm{s}_{1}^{2}}{\mathrm{~s}_{\mathrm{i}}}\right)-\mathrm{s}_{\mathrm{i}}}
$$

onde $\mathrm{N}_{\mathrm{p}}$ : indicador de competição político-partidária por ano eleitoral; $\mathrm{S}_{1}$ : é a maior componente, ou seja, a maior proporção na divisão de votos partidários; $\mathrm{S}_{\mathrm{i}}$ : é a outra ou outras componente(s) de proporção na divisão de votos partidários; $\mathrm{x}$ : é a menor componente, ou seja, a menor proporção na divisão de votos partidários.

(iii) Ideologia

Para a variável ideologia são utilizadas as medidas de posicionamento ideológico de Power e Zucco (2008), resultantes das estimativas das pesquisas de survey realizadas entre 1990 e 2005 sobre a percepção dos congressistas acerca do posicionamento ideológico de seus partidos. A escala varia de 0 (extrema esquerda) a 10 (extrema direita). A variável incorpora a média do espectro ideológico partidário referente aos períodos de 1996, 2000, 2004 e 2008.

\section{(iv) Alinhamento partidário}

Variável mensurada por meio de uma dummy definida da seguinte forma: i) partidos alinhados politicamente com o governo federal (valor $=1$ ); (ii) partidos não alinhados politicamente com o governo federal (valor $=0$ ).

(v) Ano eleitoral 
${ }^{10}$ Viana e Poz (2005) destacam que o PSF propõe uma reformulação da assistência básica e que provavelmente a oferta da nova modalidade de gestão diminuiria o gasto público com as internações hospitalares.

${ }^{11}$ Com vistas a facilitar as análises e comparações, foram aplicadas correções nos valores de acordo com a inflação do período. Assim, foi utilizado o Índice Nacional de Preços ao Consumidor Amplo (IPCA/IBGE), índice oficial do governo federal, correspondente a 31 de junho de 2011.

${ }^{12} \mathrm{O}$ logaritmo neperiano é uma medida de correção aplicada à distribuição de populações de $\mathrm{N}$ grande que visa corrigir problemas de heteroscedasticidade. Os dados de população são oriundos do IBGE.
Variável dicotômica que informa se os municípios adotaram o PSF em anos de eleições municipais com os valores: $1=\operatorname{sim}$ e $0=$ não.

\section{(vi) Proximidade geográfica}

A variável calcula o número de municípios que adotou o PSF por ano, no âmbito de cada estado, e estima se adoções posteriores estão correlacionadas com o aumento percentual de adoções anteriores. Neste caso, utiliza-se como proxy a proporção de cidades em cada unidade da federação que adotou o PSF em anos anteriores aos novos casos de adoção.

\section{(vii) Efeito Regional (Regiões Sul, Centro-Oeste, Sudeste e Nordeste)}

A medida utilizada para testar o efeito regional sobre a difusão do PSF é uma dummy que assume os seguintes valores: 1 para os municípios que pertencem a cada uma das regiões selecionadas e 0 para os municípios da região Norte.

Como controle, o modelo inclui variáveis de natureza administrativa e demográfica. Do ponto de vista administrativo, é esperado que o prefeito tenha mais incentivos para adotar o PSF na medida em que seu governo possui melhores condições financeiras, isto é, quanto melhor a capacidade fiscal da prefeitura mais propenso ele estaria para implementar o programa. Num cenário de crise das finanças públicas municipais a adoção de novas políticas impõe, no primeiro momento, a aplicação de gastos extras, o que pode ser interpretado como um ponto de veto à reforma para um grupo de gestores, mas pode representar, para outros administradores, uma solução fiscal no médio prazo ${ }^{10}$. Para mensurar a capacidade fiscal, utilizamos a variável arrecadação própria per capita $^{11}$, que mede o quão efetivo o gestor municipal exerce seu poder tributário de modo a gerar mais recursos, em seu território, para implementar e gerir as políticas públicas. O indicador consiste no total de recursos das receitas tributárias municipais - ISS, IPTU, ITBI, taxas e contribuições municipais dividido pelo número de habitantes. O cálculo é realizado com base nos valores declarados entre os anos de 1997 e 2010. Segue a fórmula da medida:

$$
\text { Arrecadação própria per capita }=\frac{\text { Total da Receita Tributária Municipal }}{\text { Total de Habitantes do Município }}
$$

O log da população ${ }^{12}$ é empregado como uma variável de controle de modo a reduzir o potencial impacto dos diferentes portes populacionais no sentido de assegurar uma melhor comparação entre os governos locais. Os municípios brasileiros são amplamente distintos em termos demográficos e o ajuste comparativo faz-se necessário para se relativizar a heterogeneidade e garantir uma menor dispersão das unidades em torno da média.

Portanto, para analisar os determinantes da difusão do Programa de Saúde na Família pelos municípios brasileiros, combinamos todas essas variáveis em um modelo de EHA. Seguindo a tradição da literatura de policy diffusion, do lado direito da equação o modelo incorpora um conjunto diversificado de variáveis que refletem os fatores internos e externos.

Adotar PSF $_{\mathrm{i}, \mathrm{t}}=f$ (Competição Política/\% de votos do eleito ${ }_{\mathrm{i}, \mathrm{t}}$, Competição Política/NEP ${ }_{\mathrm{i}, \mathrm{t}}$, Alinhamento Partidário ${ }_{\mathrm{i}, \mathrm{t}}$, Ano Eleitoral $\mathrm{i}_{\mathrm{i}, \mathrm{t}}$ Ideologia $_{\mathrm{i}, \mathrm{t}}$, População de até 17 anos $_{\mathrm{i}, \mathrm{t}}$, População a partir de 65 anos $_{\mathrm{i}, \mathrm{t}}$, Proximidade Geográfica $\mathrm{i}, \mathrm{t}$, Regiões $_{i, t}$, Capacidade Fiscal ${ }_{i, t}$, Log População $\left.i, t\right)$.

Onde Adotar PSF $_{i, t}$, é a probabilidade que um município $i$ adotará o o PSF em um ano $t$. 


\section{A implementação do PSF nos municípios}

O PSF, uma das políticas públicas mais descentralizadas do Brasil, faz parte de uma estratégia do modelo assistencial de saúde, operacionalizada mediante a implantação de equipes multiprofissionais em unidades básicas de saúde. Iniciada em 1991, a política teve como finalidade principal contribuir para a redução das mortalidades infantil e materna, principalmente nas regiões Norte e Nordeste, através da extensão de cobertura dos serviços de saúde para as áreas mais carentes do país. De acordo com Labate e Rosa (2005), o PSF gerou um importante movimento de reordenamento do modelo de atenção no Sistema Único de Saúde (SUS), alterando o foco da medicina curativa e passando a atuar mais na prevenção. Além da premissa universalista da saúde como direito de todos e dever do Estado, preconizado pela Constituição de 1988, o programa também incorpora os princípios de integralidade, qualidade, equidade e participação social. O programa funciona baseado em equipes compostas por médicos, enfermeiros, auxiliares de enfermagem e agentes comunitários de saúde, como também por dentistas. Cada equipe acompanha um mínimo de quatro mil habitantes de uma determinada área e atua com ações de promoção da saúde, prevenção, recuperação, reabilitação de doenças e agravos mais frequentes. Embora gerenciado pelo Ministério da Saúde, responsável pela operacionalização dessa política no âmbito da gestão federal do SUS, a execução é compartilhada pelos governos subnacionais e Distrito Federal. As responsabilidades do governo federal o coloca em posição de normatizador e principal financiador da política, enquanto os estados atuam na coordenação e assistência aos municípios. Estes, por sua vez, são de fato os executores do programa na medida em que acumulam atribuições como: i) implantar o modelo de atenção básica em seu território; (ii) manter a rede de unidades básicas de saúde em funcionamento; (iii) cofinanciar as ações de atenção básica; (iv) alimentar os sistemas de informação e avaliar o desempenho das suas equipes. A NOB-01 de 1993 estabelece que os municípios sejam classificados segundo condições institucionais para administrar os recursos federais concernentes à gestão dos serviços públicos e privados de saúde. A escala compreende uma divisão entre capacidade semiplena, parcial e incipiente.

Como resultado, o PSF é considerado uma referência internacional de atenção básica de saúde, sobretudo, devido aos impactos sobre a redução da mortalidade infantil (Aquino Oliveira \& Barreto 2009). Ademais, a implementação do programa também apresenta um excelente desempenho no que tange à estratégia de descentralização. É importante salientar que os governos locais atuam como atores protagonistas desta política pública, entretanto, conforme descrito, a execução pela prefeitura não pressupõe a simples adesão ao programa, mas também a um conjunto de atribuições que tornam a decisão do gestor local em participar ou não da política algo nada trivial. Para aderir ao PSF os municípios têm que implantar as normas operacionais básicas (NOB/1993 e NOB/1996) e elaborar um projeto de atenção básica à saúde que esteja em consonância com os elementos fundamentais da prestação de serviço público. Para ser aprovado o projeto deve ser apreciado pelo Conselho Municipal de Saúde e pela Secretaria Estadual de Saúde na forma da Comissão Intergestores Bipartite. Após a aprovação do projeto o município deve, entre outras atribuições, (i) selecionar e capacitar profissionais; (ii) implantar um sistema de monitoramento e avaliação do programa e (iii) definir a contrapartida municipal voltadas ao financiamento das ações do programa.

Como é possível visualizar no Gráfico 2, a evolução da participação dos governos municipais no PSF é bastante expressiva, sobretudo após 1996. Contudo, é importante destacar que após aproximadamente 15 anos das primeiras experiências, cerca de 1.000 municípios ainda não haviam aderido ao 
Gráfico 2 - Evolução do PSF nos Municípios Brasileiros, 1991-2010

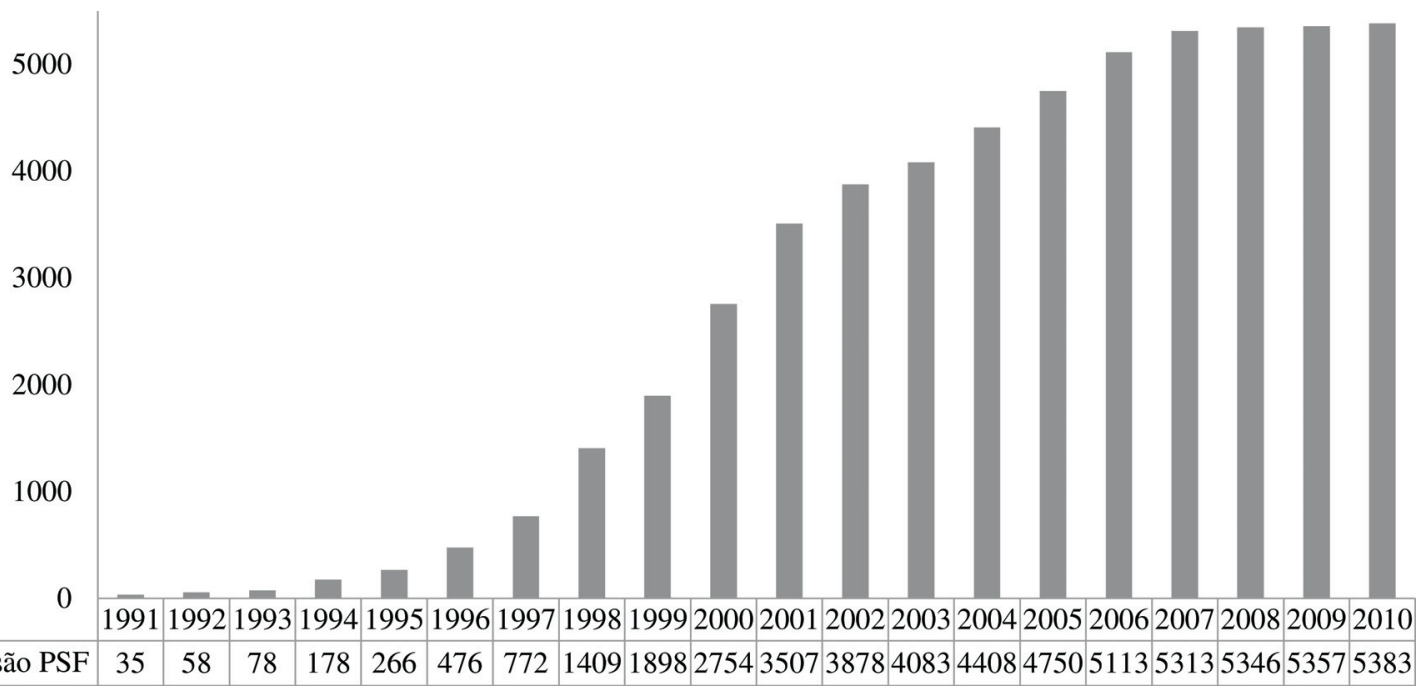

Fonte: Os autores, a partir do Cadastro Nacional de Estabelecimentos de Saúde, DataSus (8 nov. 2011).

modelo inovador de saúde. A partir de 2009, o programa passa a estar presente em quase a totalidade das municipalidades brasileiras com uma cobertura de aproximadamente $97 \%$. Atualmente cerca de 300 municípios permanecem sem adotar a política.

Entretanto, quando comparamos a distribuição dos dados por estado vemos que o padrão de difusão do PSF apresenta índices de adesão marcadamente distintos em alguns períodos do tempo analisado (Gráfico 3).

Nesse sentido, o processo de implementação desta política pública constitui um excelente laboratório para a abordagem comparada da sua difusão entre os governos locais no Brasil. Primeiro, chama a atenção o grande número de observações (municípios) disponíveis, o que propicia uma maior capacidade de generalização dos resultados da pesquisa. Aliado a isso, como os governos locais dispõem de um arcabouço institucional homogêneo, isto é, estrutura formal de organização política e jurídica, sistema eleitoral e partidário, bem como competências administrativas semelhantes, é possível focar a variação de outras características desejadas - variáveis relativas à dinâmica política municipal e aspectos estruturais (Snyder 2001). Por fim, o terceiro aspecto favorável à abordagem envolve o fato de que não é simples a decisão das prefeituras executarem o programa, haja vista que a gestão local do PSF possui uma série de atividades que demandam recursos físicos e financeiros. Em suma, as características do processo de difusão do PSF apresentam vantagens tanto metodológicas quanto teóricas que favorecem a análise dos seus determinantes.

\section{Análise dos resultados}

Para avaliar a influência de cada uma das covariáveis identificadas no estudo sobre a adoção do PSF, a Tabela 1 apresenta os coeficientes estimados assim com os respectivos erros padrão do modelo estatístico EHA. Dado a especificidade do modelo econométrico é importante esclarecer a interpretação destes coeficientes estimados com respeito a função risco. Coeficientes positivos indicam que a partir de variações na covariável a função risco aumenta, enquanto coeficientes negativos indicam o contrário, ou seja, que variações na covariável diminuem a função risco. Assim sendo, coeficientes positivos signi- 

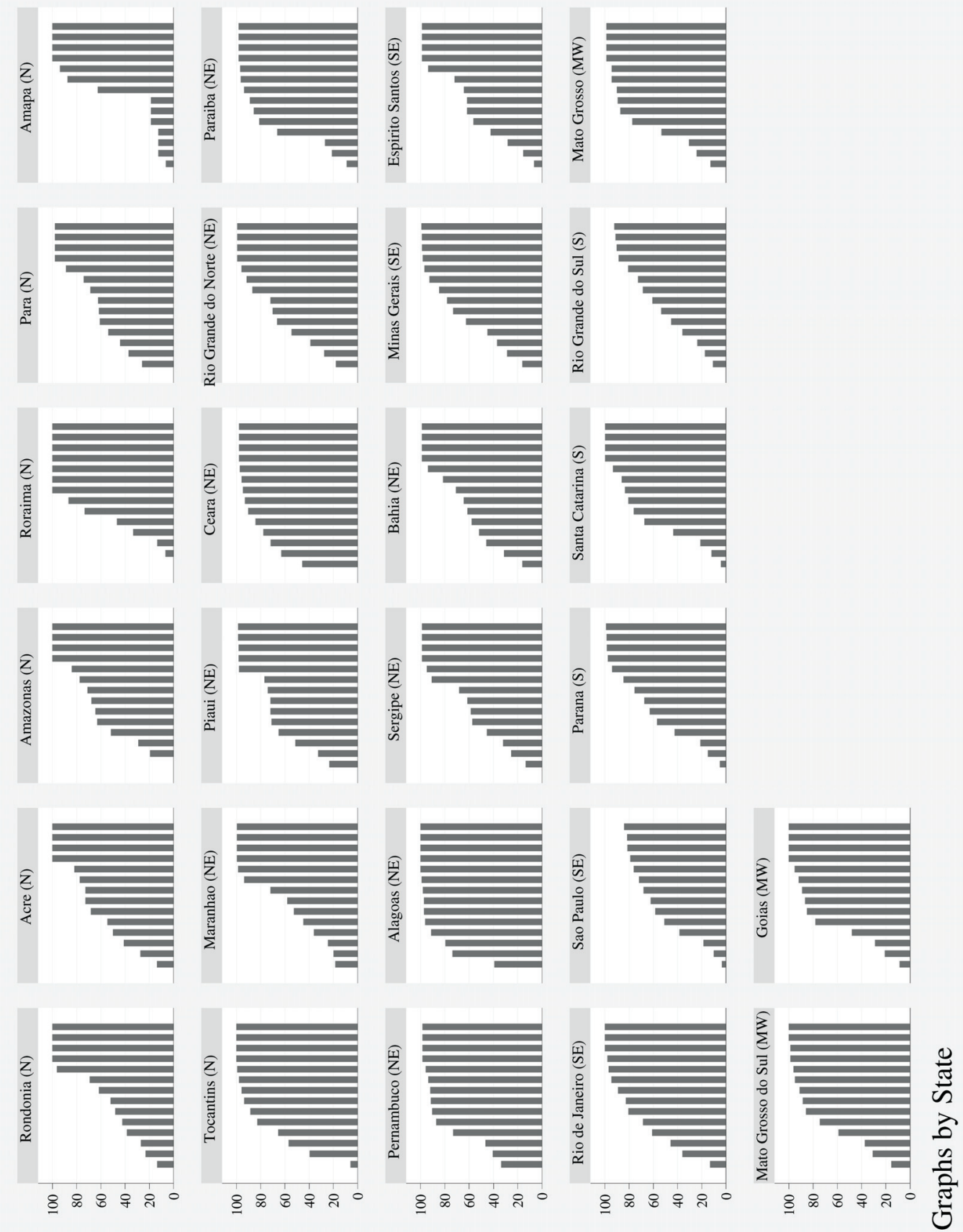

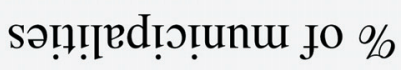


Tabela 1 - Determinantes da Difusão do PSF (1997-2010)

\begin{tabular}{lll}
\hline Variáveis Independentes & \multicolumn{2}{c}{ Coeficiente (e.p) } \\
\hline Competição Política 1 (\% de Votos do Eleito) & $0.516^{*}$ & $(4.384)$ \\
Competição Política 2 (Partidos Efetivos) & 1.297 & $(0.230)$ \\
Alinhamento Partidário & 1.131 & $(0.132)$ \\
Ano Eleitoral & $0.399^{* * *}$ & $(0.074)$ \\
Ideologia & $1.116^{*}$ & $(0.052)$ \\
População até17 anos & $1004.6^{* * *}$ & $(1.684)$ \\
População a partir de 65 anos & 41.427 & $(1.689)$ \\
Proximidade Geográfica & 1.005 & $(0.003)$ \\
Região Sul & $1.822^{*}$ & $(0.501)$ \\
Região Centro-Oeste & $2.786^{* *}$ & $(0.847)$ \\
Região Sudeste & 0.865 & $(0.232)$ \\
Região Nordeste & $0.588^{*}$ & $(0.126)$ \\
Capacidade Fiscal (Municípios) & 0.500 & $(0.333)$ \\
População (Log) & 1.092 & $(0.068)$ \\
N & 5029 & \\
Log Likelihood & -1249 & \\
Prob > Chi2 & 0.0000 & \\
\hline
\end{tabular}

Fonte: Os autores.

Notas: $\mathrm{p}<0.1, \mathrm{p}<0.05,{ }^{*} \mathrm{p}<0.01$. Erro-padrão entre parêntesis.

ficam que o tempo até a adoção é reduzido e coeficientes negativos que o tempo até a adoção é estendido ${ }^{13}$.

Os resultados da regressão relacionados à dimensão política revelam que há múltiplas interpretações sobre o efeito dessas variáveis no modelo explicativo. O resultado mais importante do estudo revela que certos fatores políticos impulsionam as taxas de adoção do PSF. A variável Competição Política 1 (Percentual de Votos do Eleito) apresenta efeito estatisticamente significante, o que indica uma correlação positiva entre o resultado das eleições municipais e as estratégias futuras de adesão a novos programas sociais. Entretanto, o coeficiente estimado da variável Competição Política 2 (Partidos Efetivos) ilustra exatamente a situação oposta, ou seja, a não influência dos votos na reestruturação do sistema de saúde pública municipal. Estes resultados sugerem que o fator percentual de vitória eleitoral afetou em maior grau a decisão de governantes aderirem ao PSF em comparação com o fator número efetivo de partidos. A variável Alinhamento Partidário, que explora possíveis conexões políticas entre as esferas governamentais, é irrelevante para o caso do PSF e, portanto, não afeta o processo de difusão aqui analisado. Especificamente, temos que o quadro de municípios alinhados com o governo federal não apresenta risco maior de adotar o programa. Um dos achados mais surpreendentes do modelo analítico é a constatação do efeito positivo da variável Ano Eleitoral. A regressão estatística demonstra que a intensidade de adoção ao PSF é mais constante no período de eleições para prefeito. $\mathrm{O}$ coeficiente possui alta significância estatística no modelo de $\mathrm{EHA}^{14}$ e confirma o impacto do ciclo político eleitoral ao mesmo tempo que sugere que atores políticos adotam políticas populares para aumentar suas chances de reeleição. A última variável de natureza política analisada é Ideologia. A estimativa positiva e significante do coeficiente confirma a hipótese que partidos políticos de esquerda são mais determinados a adotarem programas sociais inovadores em comparação com os
${ }^{14}$ As estatísticas descritivas demonstram que em média ocorreram 404 casos de adoções em anos eleitorais contra 335 casos em anos não eleitorais. Além disso, outras 210 adesões feitas em 1996 
(ano eleitoral) não estão contabilizadas no modelo estatístico do estudo devido ao recorte temporal estabelecido. partidos de centro e direita. Prefeituras que contam com governantes à esquerda do espectro ideológico partidário são mais prováveis então de adotar um sistema integrado de atendimento de saúde como o PSF.

Os fatores internos vinculados à dimensão social ilustraram resultados distintos. Uma vez que a legislação do SUS prevê que seja realizado atendimento para públicos específicos como o infanto-juvenil e pessoas idosas, testamos a possível correlação com a decisão de implantar o PSF. Os dados confirmam a hipótese que os municípios com maiores índices de População até 17 anos foram os que mais adotaram o programa. Entretanto, municípios com maiores indicadores de População a partir de 65 anos não apresentam maior propensão ao PSF em taxas maiores do que os outros municípios. A comparação entre os dois coeficientes permite afirmar que a primeira faixa etária funcionou com um indutor que influenciou a tomada de decisão dos governos locais. Uma possível explicação de caráter complementar à análise é que provavelmente há mais demanda de atendimentos à saúde para crianças, fato que gera maior pressão social ao sistema político.

Outro importante achado do estudo é a confirmação do efeito de algumas variáveis dos determinantes externos, mesmo quando controladas pelos efeitos dos determinantes internos. Para capturar este efeito, incluímos no modelo uma variável que mede o percentual dos municípios no estado que adotaram o PSF. O resultado da variável Proximidade Geográfica é nulo, o que indica que não há relação consistente entre uma maior proporção de municípios de um estado que tenha adotado o programa em anos anteriores e adoções futuras. Entretanto, em contraposição a este resultado, os coeficientes de três das quatro regiões do modelo indicam efeitos maiores de difusão do PSF na região precursora, o Nordeste, e na região Sul, onde conforme era de fato esperado haver maior emulação do programa. Contudo, o mesmo não se pode afirmar para o indicador da região Sudeste, que se mostrou insignificante. Surpreendentemente, a região Centro-Oeste foi a que registrou maior influência no incremento de casos ao longo do tempo. Depreende-se desses resultados que os municípios pertencentes às regiões Centro-Oeste apresentaram os maiores riscos de adoção, seguidos pelos municípios do Nordeste e Sul. Em outras palavras, o efeito vizinhança mostrou-se mais robusto no âmbito regional em comparação com o âmbito estadual. Conclui-se então, por exemplo, que governantes municipais de Santa Catarina foram mais influenciados por redes políticas (formais ou informais) do Rio Grande do Sul ou Paraná do que propriamente pelas redes do próprio estado.

Com relação às variáveis de controle, Capacidade Fiscal (Municípios) e População, verifica-se que as mesmas não têm efeito sobre a propensão de adotar o PSF. Apesar da relevância dos aportes fiscais para a consecução da gestão pública social e das diferenças nos portes populacionais que indiretamente indicam maior desigualdade social, o que prevaleceu na análise da difusão do PSF foram os determinantes internos e externos.

Para ilustrar a distribuição das adoções usamos o estimador de sobrevivência Kaplan-Meier. O indicador calcula a probabilidade de cada município não adotar o PSF no período 1997-2010 e, portanto, sobreviver à onda de inovação política. No contexto do estudo, conforme demonstrado no Gráfico 4, as taxas de sobrevivência municipal são máximas no tempo To (1996). Com o início e posterior progressão dos casos a estimativa de sobrevivência decresce e atinge percentual inferior a $10 \%$ no tempo T12 (2008) para depois apresentar taxas estáveis até cessar no tempo T15 (2011).

Outra forma de ilustrar a distribuição das adoções é utilizar o estimador de falha Kaplan-Meier. A disposição dos dados nesse tipo de representação é 
Gráfico 4 - Estimativa de Sobrevivência em Kaplan-Meier

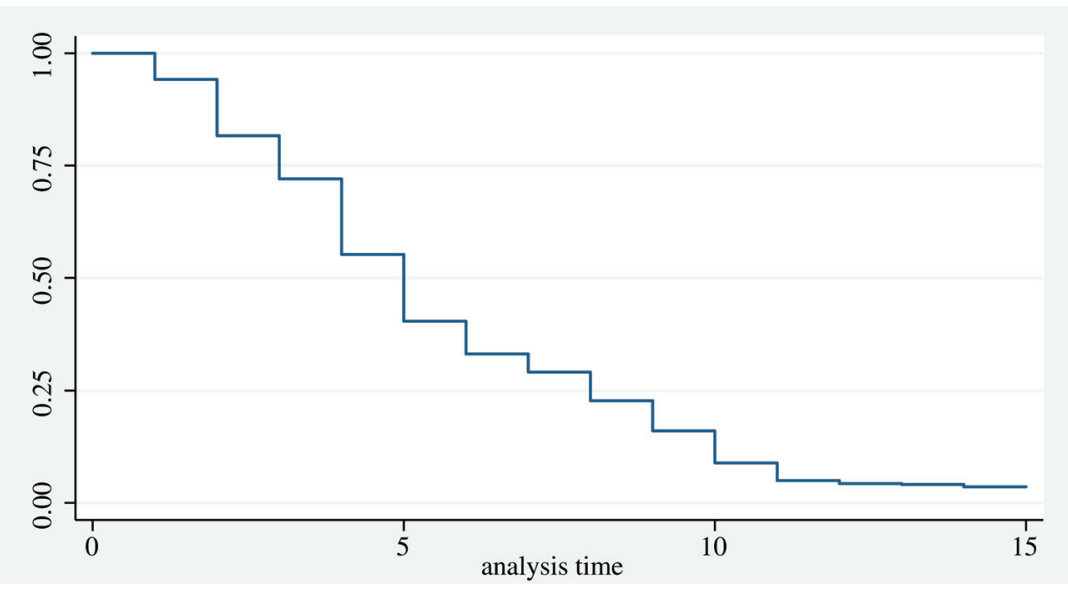

Fonte: Os autores.

diametralmente oposta à anterior e ilustra a probabilidade de um município falhar no tempo $T$ dado que o mesmo tem sobrevivido até o tempo $T$. Neste caso a probabilidade que um município adote o PSF no tempo T5 (2001) é de aproximadamente 50\% e no tempo T14 (2010), em torno de 95\% (Gráfico 5).

O Gráfico 6 apresenta a função de risco do PSF também para o período 1997-2010. As taxas de risco estimadas para cada ano foram suavizadas para permitir a ilustração de uma função de risco contínua no tempo. Os dados informam que o risco de adotar o PSF atingiu um valor máximo no tempo T8, mais precisamente em 2004 quando já se contabiliza 4.408 adoções, o equivalente a $80 \%$ dos casos. Após esse intervalo de tempo o efeito "contágio" decresceu intensamente até o último ano do tempo analisado.

De um modo geral, os resultados demonstram que não houve diminuição das estimativas de falha e sobrevivência em razão da variabilidade das variáveis independentes. Depreende-se também que o risco de adoção se manteve no tempo, o que sugere que as emulações ocorreram em decorrência da duração do

Gráfico 5 - Estimativa de Falha em Kaplan-Meier

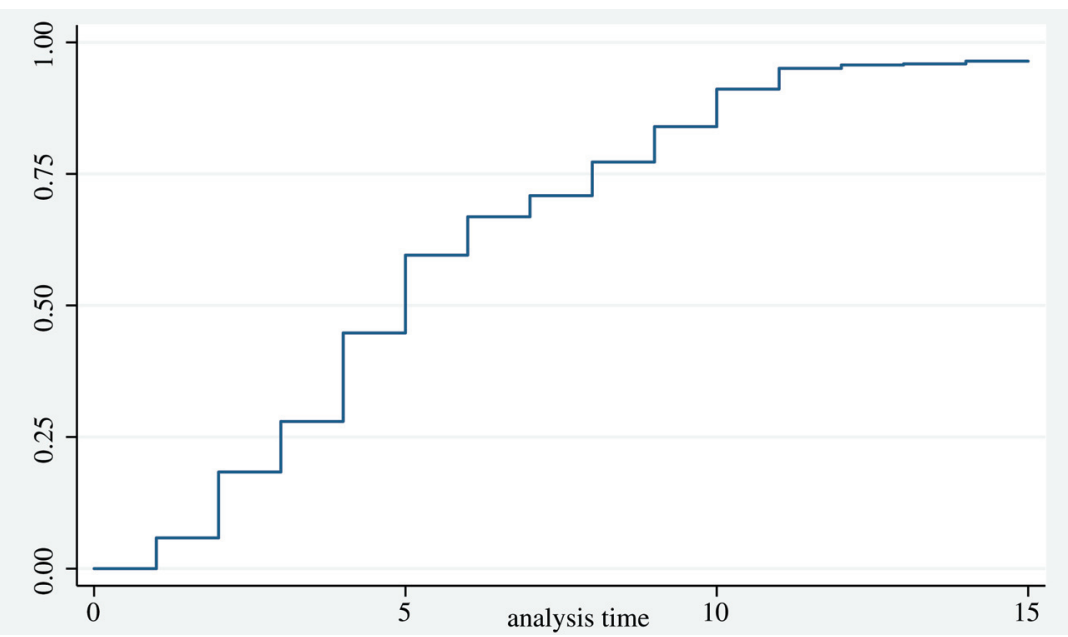

Fonte: Os autores. 


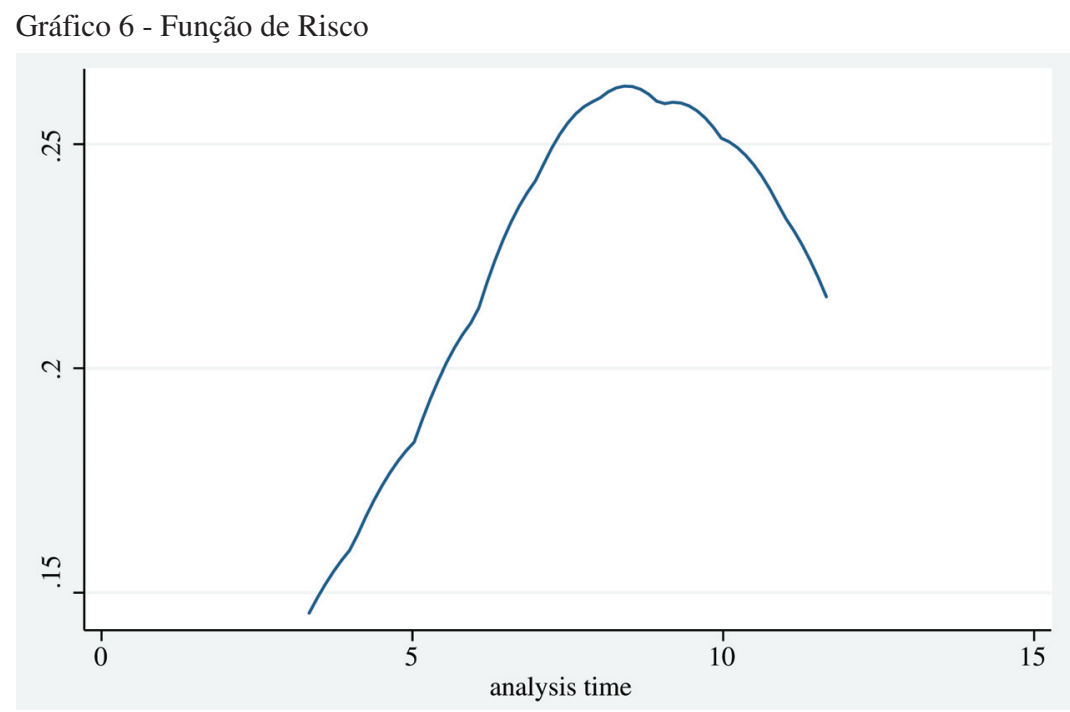

Fonte: Os autores.

evento associadas ao maior peso relativo de algumas variáveis independentes do modelo explicativo.

\section{Conclusões}

Nossa análise contribui para um melhor entendimento de aspectos fundamentais do sistema político nacional em termos da implementação de novos desenhos institucionais. A primeira conclusão de caráter geral é que programas municipais em certas condições político-institucionais afetam a estrutura da rede de proteção social do país. Mais especificamente, o estudo demonstrou a importância de se investigar o comportamento político de atores locais no complexo sistema federativo brasileiro, uma vez que identificamos distintos mecanismos direcionais que possibilitaram a disseminação do PSF. Originalmente o programa se difundiu de forma horizontal entre municípios para depois gerar pressões nas outras esferas de governo até ser federalizado num típico movimento vertical bottom-up e top-down. Nesse sentido, oferecemos aqui novas intepretações a respeito da dinâmica que regula o complexo sistema federativo do Brasil, desfazendo a visão predominante que analisa fenômenos de difusão como um processo automático de cópia ou descentralização. Ao contrário, uma parcela expressiva de governos locais demonstrou resistência ao PSF mesmo após uma década de implementação, o que evidencia a relevância dos atributos locais.

Que fatores então determinaram a adoção do PSF? Para responder à pergunta central da pesquisa, utilizamos a metodologia de análise de sobrevivência que, conforme informado anteriormente, unifica teorias rivais em um modelo econométrico para mensurar o risco do evento PSF ser replicado no sistema político. $\mathrm{O}$ artigo assim fornece uma contribuição teórico-metodológica à Ciência Política brasileira ao elaborar um estudo comparativo de tipo Large- $N$ centrado nas teorias de difusão de políticas.

Com relação aos resultados, o trabalho reforça a visão seminal de Berry e Berry (1990) sobre a relevância dos determinantes internos e determinantes externos para a explicação de como novos modelos de prestação de serviço são copiados entre governos tão distintos em termos políticos, institucionais, econômicos, populacionais e geográficos. O principal resultado é que competição política afeta a difusão do Programa Saúde da Família. Em particular, mostra- 
mos que quanto menor o percentual de votos e indiretamente a margem de vitória sobre os concorrentes, mais o prefeito eleito implantou o programa. Outro resultado importante é a confirmação de ideologia como fator indutor do processo, o que permite inferir que governantes de esquerda foram atores decisivos da emulação em contraposição aos prefeitos dos partidos de centro ou direita. $\mathrm{O}$ achado mais surpreendente da pesquisa é a alta significância estatística da variável ano eleitoral. Nos anos em que ocorreram eleições municipais foram registradas as maiores taxas de adoção. A literatura americana aponta que tradicionalmente os atores buscam adotar políticas populares em anos eleitorais para influenciar o voto dos eleitores. Entretanto, no caso do Brasil sabemos o quão complexas são as relações intergovernamentais nesse período, sobretudo para a adesão à novas políticas. Nessa perspectiva, avaliamos que mesmo diante das dificuldades institucionais o que prevaleceu nesse caso foi a estratégia de sobrevivência política de atores políticos racionais. Constatamos também que as variáveis de competição política, medida a partir do número de partidos efetivos e alinhamento partidário, não geram efeito de difusão. Embora, em geral, as coalizões políticas agrupem um grande número de partidos, o fato do partido de algum prefeito ser alinhado politicamente com o governo federal em nada afeta a decisão de adotar ou não o PSF. A mesma situação ocorre para ambientes políticos onde a concentração de votos é bastante fragmentada entre os partidos o que sugere que prefeitos eleitos resistem às inovações devido às incertezas de performance e críticas da oposição.

Outros resultados interessantes revelam a importância de se medir variáveis específicas para o caso estudado. Mesmo sendo o PSF um programa universalista, a legislação do SUS indica a necessidade de atendimento prioritário para determinadas faixas etárias. Assim, encontramos que municípios com maiores taxas percentuais de população até 17 anos foram os que mais adotaram e os com maiores taxas percentuais de população a partir de 65 foram os que menos adotaram a política. Por fim, comprovamos que o PSF se difundiu mais rapidamente entre a região precursora nordeste e as regiões Sul e principalmente Centro-Oeste. Não encontramos efeitos positivos de proximidade geográfica no recorte territorial estado, o que nos permite entender que a influência da emulação entre os municípios foi maior na unidade região, provavelmente porque os prefeitos foram influenciados por atores políticos e sociais de redes formais e informais da região e não da sua unidade federativa. Concluímos, então, que tanto fatores internos quanto externos guiaram a difusão do PSF. Os determinantes para a adoção foram o alto grau de competição política (menor percentual de votos do eleito), ideologia, ano eleitoral, demanda social específica e as regiões Nordeste, Sul e Centro-Oeste. Dito de outra forma, quando em um certo período do tempo os municípios reuniram alguns desses atributos, a adoção ocorreu. Assim, o framework teórico aplicado foi útil ao estudo porque em vez de as teorias disputarem explicações isoladas, quando unificadas no modelo EHA permitiram explicações causais em conjunto.

Os resultados reforçam, portanto, a utilidade de testar as teorias de difusão e a urgência de uma agenda de pesquisa que parece estar em crescimento. Wampler (2008) e Spada (2010), ao analisarem a adoção municipal do orçamento participativo, encontraram significância estatística para ideologia. No caso de Sugiyama (2008a), que estudou a difusão do PSF com foco nos municípios acima de 100 mil habitantes, a hipótese ideológica também foi confirmada, mas os índices de competição política não se revelaram consistentes. Em um artigo sobre a difusão do Bolsa Escola no estado de São Paulo, Coêlho (2012) também encontrou robustez na variável ideologia, tendo ainda demonstrado que competição política influenciou positivamente o processo.

Ao mesmo tempo em que nossas análises contribuem para o debate, na medida em que corroboram e refutam outros achados da literatura, reconhe- 
cemos algumas limitações do estudo. Em acordo com McCann, Shipan e Volden (2012) avaliamos que é preciso investigar mais profundamente por que um número reduzido de governos inovadores é capaz de gerar mais atividade política no sistema nacional que resulta numa difusão top-down. O caso brasileiro é uma excelente oportunidade para se avançar o debate. O país possui cerca de 300 programas sociais e se configura como um laboratório de pesquisa em potencial.

Denilson Bandeira Coêlho (denilsonbc@unb.br) é Doutor em Ciência Política pela Universidade Federal de Pernambuco (UFPE) e Professor do Instituto de Ciência Política da Universidade de Brasília (UnB). Vínculo Institucional: Instituto de Ciência Política, UnB, Brasília, DF, Brasil.

Pedro Cavalcante (cavalcante.pedro@ gmail.com) é Doutor em Ciência Política pela Universidade de Brasília (UnB) e Professor Colaborador na mesma universidade. Vínculo Institucional: Ministério do Planejamento, Orçamento e Gestão, Brasília, DF, Brasil.

Mathieu Turgeon (turgeon@ unb.br) é Doutor em Ciência Política pela Universidade do Texas em Austin (EUA) e Professor na Universidade de Brasília (UnB). Vínculo Institucional: Instituto de Ciência Política, UnB, Brasília, DF, Brasil.

\section{Referências}

Adam, S. \& Kriesi, H., 2007. The Networks and Subsystems: Change over time. In P.A. Sabatier, ed. Theories of the Policy Process. Boulder: Westview Press.

Allard, S.W., 2004. Competitive Pressures and the Emergence of Mothers' Aid Programs in the United States. Policy Studies Journal, 32(4), pp.521-544. DOI: 10.1111/j.1541-0072.2004.00079.x

Allison, P.D.,1984. Event History Analysis. Regression for longitudinal event data. In B. Entwistle, ed. Quantitative Applications in the Social Sciences. London: Sage.

Aquino, R.; Oliveira, N.F. \& Barreto, M., 2009. Impact of the Family Health Program on Infant Mortality in Brazilian Municipalities. American Journal of Public Health, 99(1), pp.87-93. DOI: 10.2105/ajph.2007.127480

Balla, S.J., 2001. Interstate Professional Associations and the Diffusion of Policy Innovations. American Politics Research, 29(3), pp.221-245. DOI: 10.1177/1532673x01293001

Baumgartner, F.R. \& Jones, B.D., 1993. Agendas and Instability in American Politics. Chicago: University of Chicago Press.

Baybeck, B.; Berry, W.D. \& Siegel, D.A., 2011. A Strategic Theory of Policy Diffusion via Intergovernmental Competition. The Journal of Politics, 73(1), pp.232-247. DOI: 10.1017/s0022381610000988

Bennett, C.J., 1991. What is Policy Convergence and What Causes It? British Journal of Political Science, 21(2), pp.215-233. DOI: $10.1017 / \mathrm{s} 0007123400006116$

Berry, F. \& Berry, W.D., 1990. State Lottery. Adoptions as Policy Innovations: An Event History Analysis. American Political Science Review, 84(2), pp.395-415. DOI: 10.2307/1963526

, 1992. Tax Innovation in the States: Capitalizing on Political Opportunity. American Journal of Political Science, 36(3), pp.715-742. DOI: $10.2307 / 2111588$

,2007. Innovation and Diffusion Models in Policy Research. In P.A. Sabatier, ed. Theories of the Policy Process. Boulder: Westview Press.

Brinks, D. \& Coppedge, M., 2006. Diffusion is no Illusion: Neighbor Emulation in the Third Wave of Democracy. Comparative Political Studies, 39(4), pp.463-489. DOI: 10.1177/0010414005276666

Boushey, G., 2010. Policy Diffusion Dynamics in America. Cambridge, UK: Cambridge University Press.

Box-Steffensmeier, J.M., 2007. Event History Modeling. In___. A Guide for Social Scientists. Cambridge, UK: Cambridge University Press.

Box-Steffensmeier, J.M. \& Jones, B.S., 1997. Time is of the Essence: Event History Models in Political Science. American Journal of Political Science, 41(4), 1414-1461. DOI: 10.2307/2960496

Buckley, J. \& Westerland, C., 2004. Duration Dependence, Functional Form, and Corrected Standard Errors: Improving EHA Models of State Policy Diffusion. State Politics and Policy Quarterly, 4(1), pp.94-113. DOI: $10.1177 / 153244000400400105$

Cleves, M.A. et al., 2008. An Introduction to Survival Analysis Using Stata. $2^{\text {nd }}$ ed. College Station: Stata Press.

Coêlho, D.B., 2012a. Political Competition and the Diffusion of Conditional Cash Transfers in Brazil. Brazilian Political Science Review, 6(2), pp.56-87. DOI: 10.1590/s1981-38212012000200003 ,2012b. Minimum Income in Brazil: A new model of innovation diffusion. In C. Pateman \& M. Murray, eds. Basic Income Worldwide: Horizons of reform. Houndmills: Palgrave Macmillan.

Cox, G. \& McCubbins, M., 1986. Electoral Politics as a Redistributive Game. Journal of Politics, 48(2), pp.370-389. DOI: $10.2307 / 2131098$

Dolowitz, D.P. \& Marsh, D. 2000. Learning from Abroad: The role of policy transfer in contemporary policy-making. Governance, 13(1), pp.5-24. DOI: 10.1111/0952-1895.00121 
Downs, G.W., 1976. Bureaucracy, Innovation, and Public Policy. Lexington: Lexington Books.

Drezner, D.W., 2001. Globalization and Policy Convergence. International Studies Review, 3(1), pp.55-78. DOI: $10.1111 / 1521-9488.00225$

Elazar, D., 1972. American Federalism. New York: Thomas Crowell.

Elkins, Z. \& Simmons, B., 2005. On Waves, Clusters, and Diffusion: A conceptual framework. Annals of the American Academy of Political and Social Science, 598(1), pp.33-51. DOI: 10.1177/0002716204272516

Fiorina, M., 1981. Retrospective Voting in American National Elections. New Haven: Yale University Press.

Glick, H., 1981. Innovation in State Judicial Administration: Effects on Court Management and Organization. American Politics Quarterly, 9(1), pp.49-69. DOI: 10.1177/1532673x8100900103

Golosov, G., 2010. The Effective Number of Parties: A New Approach. Party Politics, 16(2), pp.171-192. DOI: $10.1177 / 1354068809339538$

Gray, V., 1973. Innovation in the States: A diffusion study. American Political Science Review, 67(4), pp.1174-1185. DOI: $10.2307 / 1956539$

Grupp, F.W. \& Richards, A.R., 1975. Variations in Elite Perceptions of American States as Referents for Public Policy Making. American Political Science Review, 69(3), pp.850-858. DOI: 10.2307/1958394

Huntington, S., 1991. The Third Wave: Democratization in the late twentieth century. Norman: University of Oklahoma Press.

Ikenberry, J.G., 1990. The International Spread of Privatization Policies: Inducements, learning, and "policy bandwagoning." In E. Suleiman \& J. Waterbury, eds. The Political Economy of Public Sector Reform and Privatization. Boulder: Westview Press.

Kaufmann, R. \& Nelson, J.M., 2004. Crucial Needs Weak Incentives: Social Sector Reform, Democratization, and Globalization in Latin America. Baltimore: Johns Hopkins University Press.

Kingdon, J.W., 1995. Agendas, Alternatives, and Public Policies. $2^{\text {nd }}$ ed. New York: Longman.

Kerr, C., 1983. The Future of Industrial Societies: Convergence or continuing diversity? Cambridge, MA: Harvard University Press.

Kiewiet, D.R. \& McCubbins, M.D. 1985. Congressional Appropriations and the Electoral Connection. Journal of Politics, 47(1), pp.59-82. DOI: 10.2307/2131066

Labate, R. \& Rosa, W., 2005. Programa Saúde da Família: a construção de um novo modelo de assistência. Revista Latino-Americana de Enfermagem, 13(6), pp.1027-1034. DOI: 10.1590/s0104-11692005000600016

Light, A.R., 1978. Intergovernmental Sources of Innovation in State Administration. American Politics Quarterly, 6(2), pp.147-165. DOI: 10.1177/1532673x7800600203

Mainwaring, S.; Meneguello, R. \& Power, T., 2000. Conservative Parties, Democracy, and Economic Reform in Contemporary Brazil. In K.J. Middlebrook, ed. Conservative Parties, the Right, and Democracy in Latin America. Baltimore: Johns Hopkins University Press.

Manin, B. \& Przeworski, A., 1999. Introduction. In A. Przeworski; S. Stokes \& B. Manin, eds. Democracy, Accountability, and Representation. Cambridge, UK: Cambridge University Press.

Maravall, J.M., 1999. In A. Przeworski; S. Stokes \& B. Manin, eds. Democracy, Accountability, and Representation. Cambridge, UK: Cambridge University Press.

McCann, P.C.; Shipan, C.R. \& Volden, C., 2010. Intergovernamental Policy Diffusion: National Influence on State Policy Adoptions. In Midwest Political Science Association Meeting.

Menzel, D.C. \& Feller, I., 1977. Leadership and Interaction Patterns in the Diffusion of Innovations among the American States. Western Political Quarterly, 30(4), pp.528-536. DOI: 10.1177/106591297703000407

Mintrom, M., 1997a. The State-Local Nexus in Policy Innovation Diffusion: The Case of School Choice. Publius, 27(3), pp.41-59. DOI: $10.2307 / 3330596$

, 1997b. Policy Entrepreneurs and the Diffusion of Innovation. American Journal of Political Science, 41(3), pp.738770. DOI: $10.2307 / 2111674$

Mintrom, M. \& Vergari, S., 1998. Policy Networks and Innovation Diffusion: The case of state education reforms. Journal of Politics, 60(1), pp.126-148. DOI: 10.2307/2648004

Mooney, C., 2001. Modeling Regional Effects on State Policy Diffusion. Political Research Quarterly, 54(1), pp.103-124. DOI: $10.1177 / 106591290105400106$

Mohr, L.B., 1969. Determinants of Innovation in Organizations. American Political Science Review, 63(1), pp.111-126. DOI: .2307/1954288

Mullins, W., 1972. On the Concept of Ideology in Political Science. American Political Science Review, 66(2), pp.498-510. DOI: $10.2307 / 1957794$

Nordhaus, W., 1975. The Political Business Cycle. Review of Economic studies, 42(2), pp.169-190. DOI: 10.2307/2296528

Powell, W.W. \& Dimaggio, P.J., eds., 1991. The New Institutionalism in Organizational Analysis. Chicago: University of Chicago Press.

Power, T. \& Zucco Jr., C., 2008. Estimating Ideology of Brazilian Legislative Parties, 1990-2005: A research communication. Latin American Research Review, 44(1), pp. 218-246. DOI: 10.1353/lar.0.0072

Przeworski, S., 1985. Capitalism and Social Democracy. Cambridge, UK: Cambridge University Press.

Regens, J.L., 1980. State Policy Responses to the Energy Issue. Social Science Quarterly, 61(1), pp.44-57.

Rogers, E.M., 1995. The Diffusion of Innovations. New York: Free Press. 
Shipan, C.R. \& Volden, C., 2006. Bottom-up Federalism: The Diffusion of Antismoking Policies from U.S. Cities to States. American Journal of Political Science, 50(4), pp.825-843.

Simmons, B.A., \& Elkins, Z., 2004. The Globalization of Liberalization: Policy Diffusion in the International Political Economy. American Political Science Review, 98(1), pp.171-189. DOI: 10.1017/s0003055404001078

Spada, P., 2010. Political Competition and the Diffusion of Policy Innovations in local government: The case of Participatory Budgeting in Brazil. In Latin American Studies Association Congress. Toronto.

Stream, C., 1999. Health Reform in the States: A model of state small group health insurance market reform. Political Research Quarterly, 52(3), pp.499-525. DOI: 10.2307/449147

Snyder, R., 2001. Scaling Down: The Subnational Comparative Method. Studies in Comparative International Development, 36(1), pp.93-110. DOI: 10.1007/bf02687586

Sugiyama, N.B., 2008a. Theories of Policy Diffusion: Social sector reform in Brazil. Comparative Political Studies, 41(2), pp.193-216. DOI: $10.1177 / 0010414007300916$ , 2008b. Ideology \& Social Networks: The politics of social policy diffusion in Brazil.Latin American Research Review,43(3), pp.82-108. DOI: 10.1353/lar.0.0057

Viana, A.L.D. \& Poz, M.R.D., 2005. A reforma do sistema de saúde no Brasil e o Programa de Saúde da Família. Revista de Saúde Coletiva, 15(suplemento), pp.225-264. DOI: 10.1590/s0103-73312005000300011

Volden, C., 2006. States as Policy Laboratories: Emulating success in the children's Health Insurance Program. American Journal of Political Science, 50(2), pp.294-312. DOI: 10.1111/j.1540-5907.2006.00185.x

Walker, J.L., 1969. The Diffusion of Innovations among the American States. American Political Science Review, 63(3), pp.880-899. DOI: $10.2307 / 1954434$

Walt, S., 2000. Fads, Fevers, and Firestorms. Foreign Policy, 121, pp.34-42. DOI: 10.2307/1149617

Wampler, B., 2008. A difusão do Orçamento Participativo brasileiro: "boas práticas” devem ser promovidas? Opinião Pública, 14(1), p.65-95. DOI: 10.1590/s0104-62762008000100003

Yamaguchi, K., 1991. Event History Analysis. Applied Social Research Methods Series. V. 28. Newbury Park: Sage.

\begin{abstract}
In recent decades, the study of policy diffusion has received a great deal of attention, especially in the U.S. and in Europe. These studies have identified the role of internal (i.e., characteristics proper to the unit of analysis) and external (i.e., characteristics outside the unit of analysis) factors in explaining innovation of policy diffusion. Events of diffusion is also closely related to a time issue because the adoption often requires the simultaneous occurrence of factors in large intervals of time to take place. In this paper, we propose to explore the diffusion of social health policies in Brazil. This paper innovates by examining at the same time the role of internal and external factors using a nonconventional unit analysis to the field of study, namely local governments. To the analyses it is worth noting that the 1988 Brazilian Constitution recognizes municipalities as autonomous jurisdictions, giving them broad latitude over policymaking. What factors determine the spread of Programa Saúde da Família? To answer these question we adopt an event history analysis using data from over 5,560 municipalities over a period 1997-2010. The findings show that political competition and ideology drive the horizontal and vertical diffusion among municipalities. Surprisingly, municipal elections also drive policy emulation.
\end{abstract}

KEYWORDS: policy diffusion; family health program; municipal governments; political competition; survival analysis.

This is an Open Access article distributed under the terms of the Creative Commons Attribution Non-Commercial License which permits unrestricted non-commercial use, distribution, and reproduction in any medium provided the original work is properly cited. 